\title{
CITIZEN SCIENCE FOR WATER QUALITY MONITORING APPLYING FOSS
}

\author{
Stefan Jovanovic ${ }^{1}$, Daniela Carrion ${ }^{1}$, Maria Antonia Brovelli ${ }^{1, *}$ \\ Politecnico di Milano, Department of Civil and Environmental Engineering, Piazza Leonardo da Vinci, 20133 Milano, Italy - \\ (stefan.jovanovic, daniela.carrion, maria.brovelli)@ polimi.it,
}

Commission IV, WG IV/4

KEY WORDS: citizen science, water quality, smartphone application, free and open source, SIMILE

\begin{abstract}
:
Citizen science is an efficient tool for data collection for scientific projects. In the framework of SIMILE Interreg Italy-Switzerland project, the citizen's contribution to monitor the quality of lakes water has been envisaged. In the initial phase of this research, state of art of citizen science and water quality monitoring was investigated. The analysis of past and current projects, governed by different organizations and communities, pointed out a variety of tasks that can be accomplished by citizens. In these studies, authors stressed suitability of smartphones for the fulfilment of various assignments given to citizens. Due to that, in this research, different smartphone applications for water quality monitoring were tested and analyzed. Despite the fact that many applications for water quality monitoring are freely available, none of them is open source. Hence, this paper is proposing the design of a new application, for the purposes of SIMILE project, that will be free and open source, addressing not just users but also developers giving them a possibility for customization and improvement.
\end{abstract}

\section{INTRODUCTION}

\subsection{Citizen science}

According to Oxford English Dictionary citizen science is defined as "Scientific work undertaken by members of general public, often in collaboration with or under the direction of professional scientists and scientific institutions" (OED, 2019). The involvement of public members in scientific researches/projects created an efficient 'tool' during the years, which gave valuable scientific results (Garbarino \& Mason, 2016). Citizen science projects are usually driven by the same four common features (Flagg, 2016): a) anyone can participate, b) data are collected under the same protocols in order to preserve their quality, c) collected data can be helpful in real case studies and d) data/results are publicly shared.

According to Fritz, et al. (2017) the engagement of citizens in a scientific project is characterized by three key stages: recruitment, motivation and retention. The recruitment starts with the targeting of the potential interest groups. They can be reached using various means of communication, such as social media, press and email. Making connections with educational institutions (schools, universities) is a potential way to activate students to take part in citizen science projects (OlteanuRaimond, et al., 2017). In order to keep users motivated, which is not an easy task, the practice showed several methods. First of all, the data collection performed by citizens should be simplified as much as possible and, preferably, it should be planned to be feasible in association with the users' regular activities. This should be valid also for the requested devices/tools. Moreover, gamification is one way to retain the interest of contributors, adding an element of fun while executing the given tasks. Finally, potential rewards can additionally motivate citizens to become a part of the project (Nielsen, 2006).

The study of Kullenberg \& Kasperowski (2016) showed that citizen science gave the best results in researches on biology, ecology and conservation. Beside these fields, citizen science reached great success in the field of Volunteered Geographic Information (VGI), e.g. with OpenStreetMap (OSM) project. For the case study of this paper, the task of citizen scientists will be in the framework of environmental conservation and VGI.

\subsection{Citizen science for water quality monitoring}

Water, as one of the vital elements for human existence, has become a scarce resource (Liu, et al., 2017). Its quality and quantity is continuously diminishing. This fact caused the raise of the interest for the involvement of citizen science in water quality monitoring during the years. As a result, the number of published papers per year shows an increasing trend in the past 30 years (Figure 1).

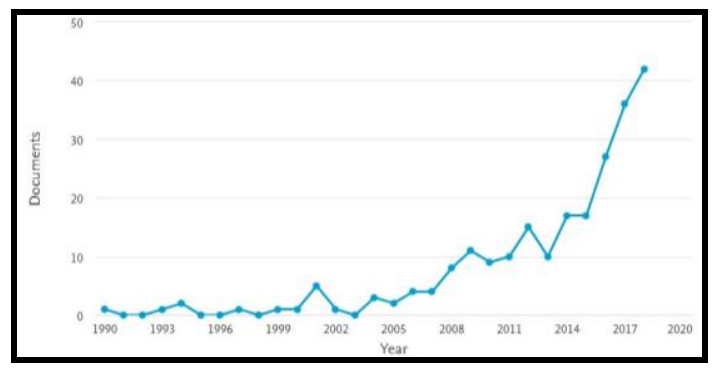

Figure 1: Number of published papers related to water quality and citizen science (Elsevier, 2019)

\footnotetext{
* Corresponding author
} 
With respect to their spatial distribution, United States are leading, followed by United Kingdom, Canada and Italy, which occupies a promising fourth position (Figure 2).

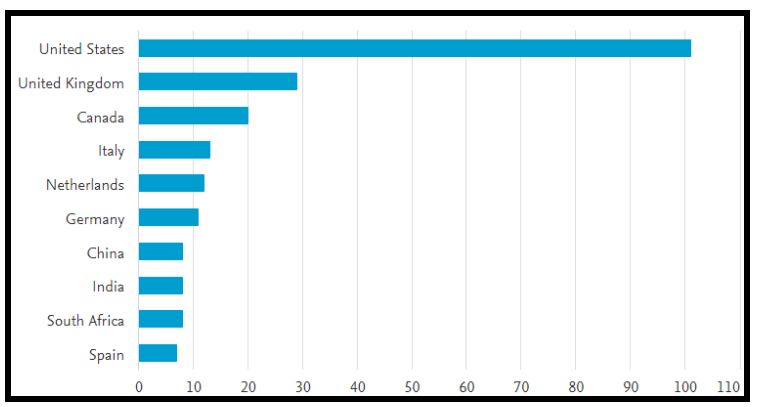

Figure 2: Number of published papers related to water quality and citizen science by Country (Elsevier, 2019)

A review of the projects dealing with water quality monitoring is presented in the following paragraph. MONOCLE project, sponsored by European Union's H2020 program for research (hereafter EU H2020), unites 12 partners (universities and research centers) to create in situ observation solutions (incorporated with citizen science observation) for Earth Observation (EO) of optical water quality in inland and transitional waters (Plymoth Marine Laboratory, 2019). Inside MONOCLE, the citizen science projects FreshWater Watch and kdUINO are included and supported. FreshWater Watch is a water quality monitoring program that examines the drivers and causes of freshwater degradation. kdUINO develops low cost devices to measure water transparency and the task of citizens corresponds to the deployment of these devices in a broad range of locations.

Other projects related to water quality (BrooklynAtlantis, Citclops, Crowdwater, HSBC Water Programme), governed by different organizations and communities, point out a variety of tasks that can be accomplished by citizens. Citizens' role in some of these project is, for example:

- Recognition of images (e.g. taken with robot boat) to verify whether the wild life exists or not in the water (BrooklynAtlantis, 2012);

- Water sample collection for localization of clean water habitats in urban landscapes (McGoff, et al., 2017);

- Micro and macroscale nutrient concentration monitoring (Loiselle, et al., 2016; Yuchao, et al., 2017);

- Quantification of anthropogenic litter on lake beaches (Vincent, et al., 2017);

- Water turbidity and water clarity monitoring [(Leeuw \& Boss, 2018); (Seafarers, et al., 2017)].

For most of these projects, the use of a smartphone is needed to collect and/or store information acquired by citizens. There are many reasons why mobile phones can be a key tool to be exploited in citizen science, some of them are (Lane, et al., 2010):

1) Availability of many different sensors embedded in them (cheap and affordable);

2) Possibility to adjust applications in order to exploit sensors;

3) Availability of Internet connection, allowing for the possibility to: deliver the applications to a large population; share the data through dedicated platforms; post-process the data in back-end servers.

\section{SIMILE PROJECT: CASE STUDY}

SIMILE Interreg Italy-Switzerland project (Sistema informativo per il monitoraggio integrato dei laghi insubrici e dei loro ecosistemi, Information System for the integrated monitoring of Insubric Lakes and of their ecosystems) is dedicated to the monitoring of the three major lakes in the Sub-Alpine area: Lake Como, Lake Maggiore and Lake Lugano (for the area of interest see Figure 3). The project is sponsored by the interregional (Interreg Europe) cross border program between Italy and Switzerland for the years 2014-2020. The main objective of the project is to support decision making and policy definition for the area of the interest, through an advanced information system, based on data from innovative approaches for monitoring lakes.

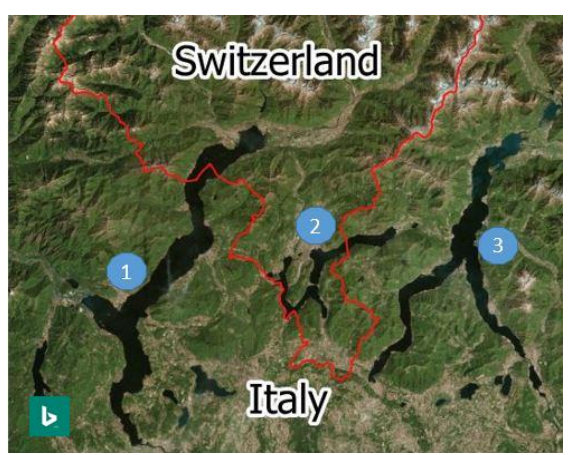

Figure 3: The area of interest; 1 - Lake Maggiore, 2 - Lake Lugano, 3 - Lake Como (Hijmans, 2019)

The innovative approaches addressed by SIMILE include:

1. Sensors (in-situ monitoring),

2. Satellite maps,

3. Citizen science.

In-situ monitoring envisages continuous acquisition of limnological (temperature of the water, $\mathrm{pH}$ factor, salinity, dissolved oxygen, chlorophyll-a,...) and meteorological parameters, which can be obtained with stationary and relocatable platforms equipped with dedicated sensors. This is complemented by satellite monitoring, as a support for traditional discrete monitoring, allowing to extend the spatial and temporal survey scales and to develop early warning systems with respect to some critical issues affecting lakes, such as algal blooms. Products of European Copernicus program Sentinel 2A, 2B and 3, as well as Landsat 8 , will be used to produce maps of surface water quality (showing information of Chlorophyll-a, Total Suspended Solids and Transparency of water). An additional acquisition method relies on the personal contribution of citizens. In the framework of the project, a dedicated mobile application is being designed to allow citizens to contribute to the monitoring of the lakes under study, with respect to their specific needs. Those data will be available in real time through a Web service.

As a part of SIMILE project, a survey has been conducted among Italian citizens (living in the area of interest) to evaluate their awareness for the protection of the lakes' environment. The first collected results showed high interest of participants in having a simple application for data collection and easy 
accessible internet real-time data visualization. In the framework of SIMILE meetings, it was possible to acknowledge that the stakeholders involved in the lake management and in the exploitation of its value (e.g. for tourism and sports) shared the same interest.

\section{ANALYSIS OF EXISTING MOBILE APPLICATIONS FOR WATER QUALITY MONITORING}

For the purpose of this research, the following applications were taken into account and tested:

$\begin{array}{ll}\text { - } & \text { EyeOnWater; } \\ \text { - } & \text { HydroColor; } \\ \text { - } & \text { SecchiApp; } \\ \text { - } & \text { bloomWatch; } \\ \text { - } & \text { iQwtr; } \\ \text { - } & \text { Lake Observer. }\end{array}$

For each of them, the following questions were answered:

1) How does the application work (what is the workflow in data collection)?

2) Which and how many observables are collected/stored with the application?

3) Does the application require additional tool(s)/equipment?

4) How collected data can be accessed?

5) Are the data free and open?

6) Who is/are the developer(s) of the application?

7) Is the application free of charge?

8) Is the application open source?

9) Is the application user friendly or is it complex to use?

10) What are pros and cons of application?

EyeOnWater is a smartphone application created for the estimation of surface water color. The application uses smartphones' camera, GPS receiver, accelerometer and clock to acquire data. For successful collection of data, the user is requested to take a picture following specific instructions that are provided through an introductory video when running the application. The instructions refer mainly to the position of the smartphone with respect to the water surface and to the sun position while taking the image (Busch, et al., 2016). Once the picture is captured (Figure $4 a$ ), the user assigns a color to the image from digital color comparator (Figure $4 b$ ) scale of Forel$\mathrm{Ule}^{1}$ (hereafter FU), which is provided on the screen within the application (Novoa, et al., 2013). Afterwards, the user is asked to give the answers to two questions, i.e. whether it is raining or not and whether the water bottom is visible or not. At the end, the captured image with the selected color index and given answers are stored on the projects' server (Figure 4c). Additional tools and equipment are not mandatory, optionally, the user can insert the value of Secchi depth and observed value of FU index. In that case, Secchi disk ${ }^{2}$ and paper/plastic based

${ }^{1}$ Forel Ule (FU) Scale is a method to approximately determine the color of water bodies. FU color index spans from 1 to 21 , where indices 1, 10 and 21 represent indigo blue, green and cola brown, respectively. FU color index gives an indication of the transparency of the water and thus helps to classify gross biological activities.

2 Secchi depth is a measure of water turbidity/clarity. Its acquisition requires the Secchi disk. Secchi disk is a black
FU scale palette (which can be more reliable than the one provided within the application) would be necessary, as external additional tools. Data are visualized, accessible and freely available for download at http://www.citclops.eu. Downloaded data are stored as .csv file containing the following information: id of input, ids' status, input date, latitude, longitude, device id, device model, viewing angle, rain (yes/no), bottom visibility (yes/no), assigned FU color index by user, processed FU color index (Novoa, et al., 2015), observed FU color index (optionally) (Citclops, 2014), Secchi depth (optionally) and URL of image.

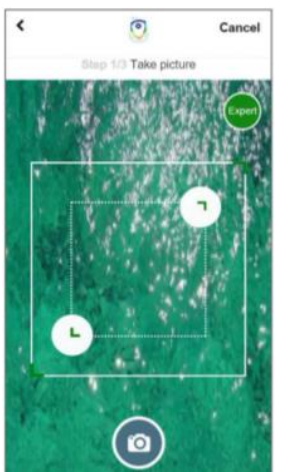

a) Image capture

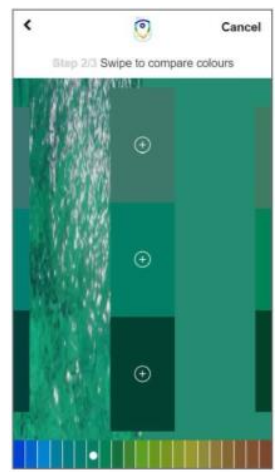

b) Color picking

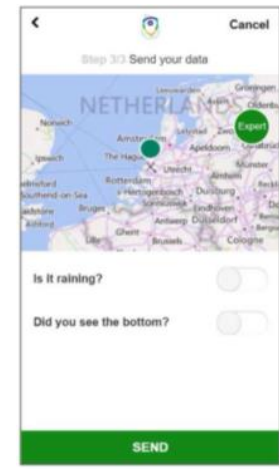

c) Additional information insertion and data upload
Figure 4: The workflow of EyeOnWater application (Source: Maris B.V. (2019). EyeOnWater(1.5.9.)[Mobile application software]. Retrieved from http://itunes.apple.com )

The application with its supporting website was developed by Royal Netherlands Institute for Sea Research, Vrije University of Amsterdam, MARIS and Veeder within Citclops project (EU H2020). EyeOnWater is available on App Store and Google play for free. It is not an open source application. Regarding complexity of usage, one might say that it is easy to handle. The application does not allow the user to take images if quality controls are not satisfied, i.e. if the smartphone is not in the proper position and orientation with respect to the water and sun position. A drawback of the application is that the post processing part returns just the FU value, while parameters like turbidity, water clarity and total suspended solids are not available, but they could be computed to provide additional value.

HydroColor is an application that uses the smartphone's sensors to measure reflectance of the water and to derive various parameters that describe water quality (Leeuw \& Boss, 2018). The same group of sensors used in EyeOnWater is exploited within this application. To get the value of reflectance, a set of three images is required, i.e. an image of photographers' gray card (additional equipment), an image of the sky and, finally, an image of the water surface (Figure 5). The user should follow the guidelines within the application in order to collect the pictures in a correct way, i.e. to respect the position and orientation of the smartphone with respect to the observed surface and with respect to the sun.

and white plate with diameter of 30 centimeters. It is attached to the rope. The rope represents a tape meter. The disk is submerged into the water until it can no longer be seen. The value of depth read from the rope is called Secchi depth. 


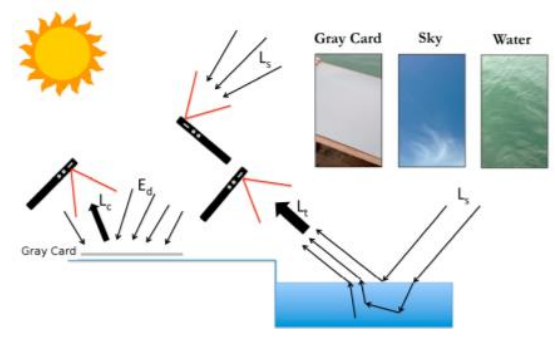

Figure 5: The data acquisition schema of HydroColor (Source: (Leeuw \& Boss, 2018))

The captured images are the only input data. The computation is done in post-processing within the application. The results are stored inside the internal memory of the smartphone. The stored file contains following information: latitude, longitude, date, time, sun zenith, sun azimuth, device zenith, exposure value, remote sensing reflectance, turbidity, suspended particle matter concentration and back scattering coefficient. The application is developed by Thomas Leeuw and Emmanuel Boss, members of Maine In-situ Sound and Color Lab - School of Marine Sciences (University of Maine). The big advantage of this application is the fact that the smartphone is used as an objective sensor, thanks to the automatic calculation of the reflectance, without requesting the user judgement. In addition, this application derives a variety of output parameters. Some of them are computed using models, which could not fit to every water body, thus, it must be considered that the application, as it is, could not be valid everywhere (Boss, et al., 2009). The user can capture images even though the smartphone is not oriented correctly, i.e. the application does not forbid this automatically (while, for example, EyeOnWater prevented the user to acquire data in a wrong way). This can be considered as a drawback, but this could also be considered for future improvement. The application is available on App Store and Google Play for $3.5 €$. It is not an open source application. Since the user is requested to collect just three images, HydroColor can be considered as a user friendly application.

SecchiApp is a smartphone application (Figure 6a) that allows the user to record values of observed Secchi depths and to store them on the projects' online data base (Seafarers, et al., 2017). Using smartphones' inbuilt GPS receiver the location is added to observed Secchi depth (Figure 6b) data (to collect it, Secchi disk (Figure 6c) is mandatory).

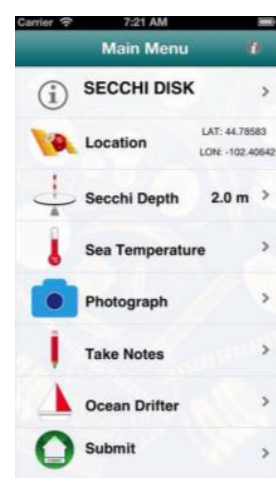

a)Application interface

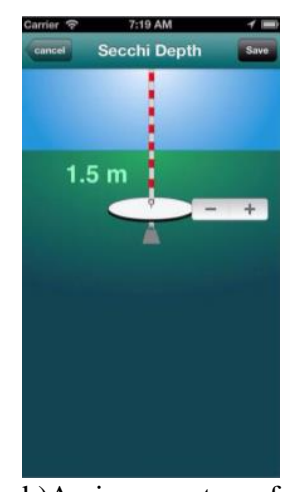

b)Assignement of Secchi Depth within app
Figure 6: The application layout and and example of Secchi disk usage (Source: University of Plymoth Enterprise Ltd. (2019). SecchiApp(1.36)[Mobile application software]. Retrieved from http://itunes.apple.com)

Optionally, SecchiApp allows the user to provide additional information such as water temperature and pictures of the observed area. Besides, SecchiApp provides instructions and descriptions on how to collect the Secchi depth correctly. Submitted record(s) (via internet) are visualized on the projects' geoportal (www.playingwithdata.com/secchi-disk-project). The contributor can download (in .csv and .pdf format) the data published by himself only. This application is developed by the University of Plymoth, AeroCODE and Pixalytics. Developers are using collected data to monitor Phytoplankton on global scale. The application is available on App Store, Google Play and Microsoft platform for free. SecchiApp is not an open source application. It is easy to use (only one observable is measured) which is its main advantage. However, the Secchi disk availability is necessary and the measurement of its depth visibility relies on the subjective judgement of the user, which might be a drawback.

bloomWatch is a smartphone application created to track cyanobacteria, by monitoring the growth of the blooms in the inland waters. It is very simple to use, since consists of a form to be filled. Data are stored with respect to "workspaces" and each water body should have its own. The user can add information to an existing workspace or he can create a new one. The filling of several attributes is requested, related to: date, location, water body accessibility, weather and surface conditions during survey and approximate extent of the bloom. In the last stage of the survey, three images should be captured. The first image should focus on the extent of the bloom, the second one on blooms' surroundings and the third one on the blooms' sample taken from water (if the user is able to take it with the appropriate equipment). The process of geotagging is included at this stage as well, hence, all images are geo-located (using the smartphones' GPS receiver). Data are freely available on www.CitSci.org, a web platform which is currently hosting 772 citizen science projects. Besides free and open data, this platform allows users to create and handle projects, as well as to analyze the collected data. The application is produced under the supervision of not-for-profit New England Interstate Water Pollution Commission (made of 35 members from governmental, public and private agencies from US states Connecticut, Maine, Massachusetts, New Hampshire, New York, Rhode Island and Vermont). The application is available on App Store and Google Play for free. It is not open source. Minor changes should be done in order to make it valid for other regions (e.g. in current version only US States are considered as available variables in fields to be filled by the user).

iQwtr is a smartphone application (coupled with iQwtr device) created to monitor water turbidity. iQwtr device (necessary equipment) is a $1450 \mathrm{ml}$ container, having photogrammetric markers inside itself. Combining these tools (the application and the device), the Secchi depth method could be substituted. The guidelines for successful data collection are given together with the iQwtr device (not within the application). The first step corresponds to filling the iQwtr device with a water sample. The second step requires the collection of images, placing the smartphone on the center of the iQwtr device (see Figure 5). 


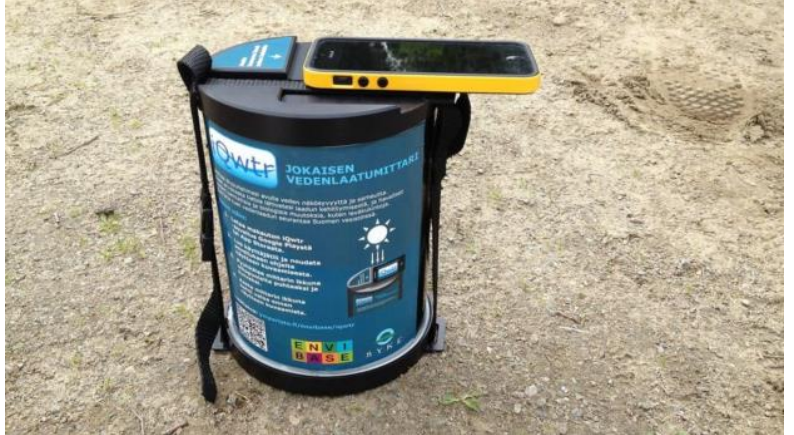

Figure 7: The iQwtr device (Bonnor, 2015)

According to the validation report provided by Finnish Environmental institute (Kaukonen \& Bruun, 2015), light conditions inside the device are crucial, thus one should be careful on how to place/orientate it. After the images are taken, the post-processing is done on the server. Secchi depth and water turbidity are returned as outputs. All measurements are automatically geo-located (using the smartphones' GPS, which must be enabled). iQwtr is developed by BlueLeg Monitor BV in cooperation with Water Insight BV and the Finnish environmental research organization Syke. The advantages of this application are: the method is completely objective; water samples do not have to be taken in deep water (case of Secchi disk usage).

The application is freely available on Aptoide platform and it is not an open source app. Collected data are accessible just within the application. The possibility to access the data on a geoportal or on sharing platform would be an asset.

Lake Observer is a smartphone application for research scientists and citizens to record lake and water quality observations. The application itself works as a form (Figure 8). The user has the possibility to create a new project or to make a contribution to an already existing one. Beside data related to water quality, this application allows the user to store data referring to weather conditions and aquatic vegetation. All observables that can be stored within Lake Observer are listed as follows:

1. Water / Ice;

1.1. Water Quality (Temperature, Conductivity, $\mathrm{pH}$, Dissolved $\mathrm{O}_{2}$, Turbidity, Chlorophyll, Location, Date, Time)

1.2. Secchi Depth (Secchi depth, Water depth, Surface conditions, Light condition, Bottom visibility, Location, Date, Time)

1.3. Ice Cover (Photo, Location, Date, Time)

2. Weather;

2.1. Air Temperature (Temperature, Location, Date, Time)

2.2. Precipitation (Category of precipitation, Period, Amount, Location, Date, Time)

2.3. Cloud Cover (Percentage, Location, Date, Time)

2.4. Wind (Speed, Location, Date, Time)

3. Aquatic Vegetation

3.1. Algae (Environment, Transparency, Description, Extent of Bloom, Algae Type, Photo, Location, Date, Time)

3.2. Macrophytes (Environment, Event, Species, Photo, Location, Date, Time)
3.3. Metaphyton (Colony shape, Colony position, Colony color, Location, Date, Time)

Regarding smartphones' sensors, the application uses GPS receiver to geo-locate observations. For some observations, the camera is used as well. Additional equipment is mandatory for certain number of observables. Stored data are published on Lake Observer platform and they are free and open. The application is available on Google Play and App Store for free and it is not open source. It was created by members of the Global Lake Ecological Observatory Network (GLEON). Regarding complexity of usage, it can be considered as user friendly.

A summary of applications' reviews is showed in Table 1. The 'User friendly' criterion is based on subjective perception of the reviewer. The maximum value for this 'feature' is 5 . The following acronyms are used to define data accessibility: OW data available on projects' web-site, WA - data available within application.

Table 1: Summary of the applications review (values for category 'User friendly' range from 1-bad to 5-excellent, acronyms for data accessibility $\mathrm{OW}$-data available on projects' web site, WA-data available within application)

\begin{tabular}{|c|c|c|c|c|c|}
\hline Application & $\begin{array}{c}\text { User } \\
\text { friendly }\end{array}$ & Cost & $\begin{array}{c}\text { Open } \\
\text { Source }\end{array}$ & $\begin{array}{c}\text { Free and } \\
\text { Open data }\end{array}$ & $\begin{array}{c}\text { Data } \\
\text { accessibility }\end{array}$ \\
\hline EyeOnWater & 4 & Free & No & Yes & OW \\
\hline Hydro Color & 4 & $3.5 €$ & No & No & WA \\
\hline SecchiApp & 5 & Free & No & No & OW \\
\hline bloomWatch & 4 & Free & No & Yes & WA \\
\hline iQwtr & 4 & Free & No & No & WA \\
\hline Lake Observer & 5 & Free & No & Yes & OW \\
\hline
\end{tabular}

\section{SMARTPHONE APPLICATION DESIGN FOR SIMILE PROJECT}

The review presented in the previous section showed that none of the considered available applications for water quality monitoring is open source. In this paper, the design of a new application, free and open source, is proposed. The new application should respect the following criteria:

- To be user friendly (during collection and exploitation phase);

- $\quad$ To be useful for different purposes (both for scientific and non-scientific society);

To be compatible with a Web platform;

To provide user support (instructions and guidelines);

To be able to work offline;

To be compatible with Android, iOS and Windows;

To be able to protect personal data;

To be free and open source.

\subsection{European Water Framework Policy}

The application should be able to monitor parameters defined by Water Framework Policy, established by Directive 2000/60/EC of the European Commission and of the Council of 23 October 2000. Quality elements for classification of the ecological status of lakes, which can be found in Solimini, et al. (2006), include biological elements, hydro-morphological elements supporting the biological elements, chemical and physico-chemical elements supporting the biological elements. According to the agreement with IRSA CNR (Istituto di Ricerca sulle Acque, Consiglio Nazionale delle Ricerche - 
Water Research Institute, National Research Council of Italy) among those quality elements, the following ones were selected to be measured with the help of citizen science: water transparency, thermal conditions, algae blooms and pollutants.

\subsection{Stakeholders involved in SIMILE project}

Many different stakeholders will be involved in SIMILE project. The list of associations and organizations existing over the area of interest that will be asked to participate is given as follows:

Associations of fishermen;

Rowing teams;

Swimming and scuba diving clubs;

Navigation companies;

Local Civil Protection teams (Protezione Civile);

Local and regional authorities;

Schools/Universities.

All of them have a common interest in monitoring and preserving the water quality of the lakes of the area of interest. The involved stakeholders will contribute to the project collecting data with the application. However, their contribution will vary depending on their equipment, skills and habits. For example, those with the availability of vessels, e.g. fishermen, will be asked to collect data with specific tools (like thermometers, or Secchi disks, provided for free) and in particular locations, such as deep water.

The application can be considered as an educational tool as well. Students could learn how to become a part of the environmental conservation projects through practical sessions. During these workshops, they will learn how to make their own Secchi disk and how to use it properly.

\subsection{Architecture, development and workflow of the application}

As mentioned before, the new smartphone application will be used mainly for the water quality data collection and visualization. It will be complemented with a web application. Beside contributors (data surveyors), the web application will be useful also for people interested only in visualization, analysis and/or download of the observed/processed data. Thus, the client side will include a smartphone mobile application (adjusted for iOS, Android and Windows platforms) and a web application (allowing data visualization and download). The server side will be constituted by three major elements (Figure 9 ), which may coexist in the same hardware or not, depending on the project management. The three elements are servers to host, install and execute the smartphone and web application; a database for storing data observations and a workstation for the post processing of collected images (e.g. the computation of water turbidity).

Client and server side will communicate using HTTP protocol. Initially, the clients' request will be sent to the host server. This request may consist in data entry (e.g. if user wants to upload collected observations), data retrieval (e.g. if user wants to access or download data) and personal data management. Depending on the needed action, the dedicated server will be involved. For instance, if a user wants to delete its account, host server will address this action to the database server. As a return, the user will get a feedback message that the operation is executed successfully. In any case, the client side will receive the response in (JavaScript Object Notation) JSON or HTML page format, depending on the application which is used, mobile or web. JSON format is convenient for the purposes of the designed application: it is open standard format and it is compatible with the open source libraries for web mapping (e.g. Leaflet (https://leaflet.com)) and servers for sharing geospatial data (e.g. GeoServer (http://geoserver.org)).

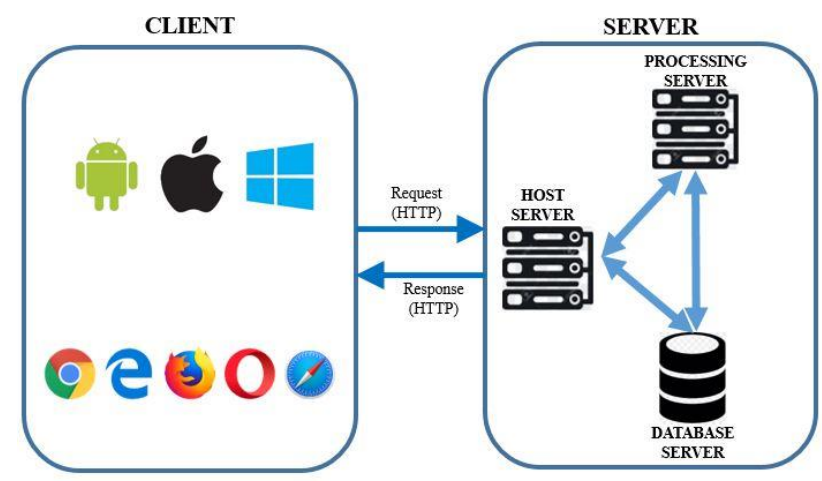

Figure 9: The architecture of the new application

Beside creating a free and open source application, the idea is also to use free and open source software and libraries while developing it. As a reference, the Land Cover Collector smartphone and web application is considered (Brovelli, et al., 2018), which has been developed in the framework of free and open source software. The Land Cover Collector is based on the Apache Cordova mobile application development framework (https://cordova.apache.org/). This is the framework that is planned to be used for SIMILE: it allows to create a unique codebase that is compatible with different application platforms (Android, iOS and Windows). Given that data could be collected in remote places where internet connection may drop off, it is required to allow users to store data locally. One of the potential technical solutions for data storage is PouchDB (https://pouchdb.com/), which enables applications to store data in offline regime and then to synchronize them with CouchDB once the internet connection is available (http://couchdb.apache.org/).

General Data Protection Regulation (GDPR) will be taken into account in the development of the new application. This regulation sets guidelines for the collection and processing of personal information from individuals who live in European Union. Accordingly, the application will be designed in such a way that users will be in control of their personal data. Users will have the possibility to be informed about the GDPR and their rights directly from the application and projects' website. The usage of personal data for the project purposes will be visible and transparent. Users will have the possibility to prevent processing of their personal data and to ask for their withdrawal in every moment. Depending on the personal information that will be collected and on the user target the issues related to GDPR may differ.

The workflow (Figure 10) of the application is divided into few steps: data collection, data storage and data visualization. After launching the application, the location service will be requested automatically to be enabled. Then, the user will have to choose one or multiple tasks (differing by complexity) in order to start data collection. Task 1 is the simplest: it requires the lowest expertise in water quality monitoring and additional equipment is not required. The goal of the task is the collection of one or 
more images (with associated location) showing pollutants (algae blooms, anthropogenic substances) in the lake water. Task 2 refers to the measurement of the water temperature, while task 3 to the measurement of Secchi depth.

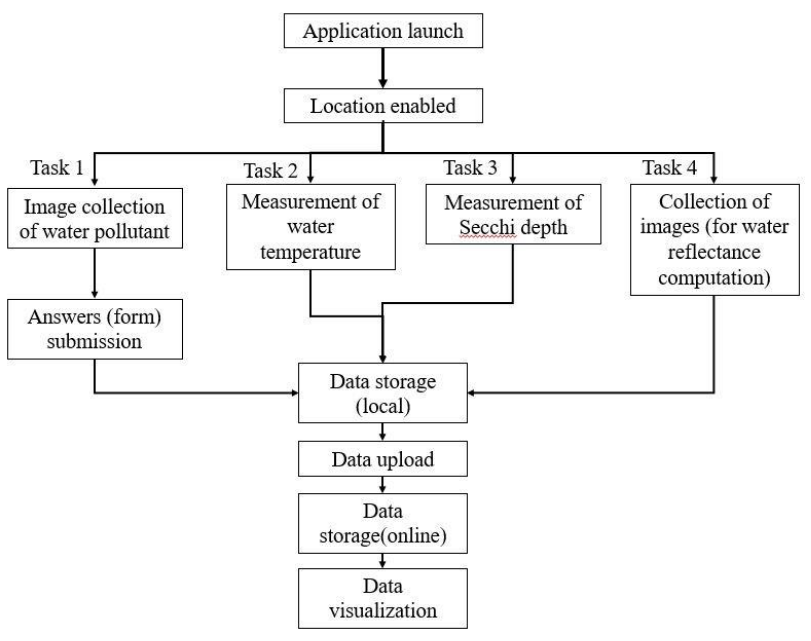

Figure 10: The workflow of data-collection in the application

To fulfill those two tasks, additional equipment is mandatory (thermometer and Secchi disk), which will be provided for free to specific groups of users who will agree and who will have the required means (e.g. vessels) and level of expertise. Task 4 is devoted to image collection of the water surface, under certain conditions. Those conditions are related to the orientation of the smartphone with respect to the sun and to the inclination of the smartphone with respect to the water surface. Data from this level will be used by CNR IREA (Istituto per il rilevamento elettromagnetico dell'ambiente, Consiglio Nazionale delle Ricerche - Institute for electro-magnetic remote sensing of environment, National Research Council of Italy) and CNR IRSA to perform post-processing, i.e. to compute water turbidity and suspended particle matter concentration. The parameters for image acquisition will be based on scientific literature and agreed with CNR IREA and IRSA. As mentioned before, the user is not obliged to fulfill all tasks, thus, after completing at least one of them, data will be stored. At first, data will be saved within the memory of the device and afterwards on the server. Then, the user will have the possibility to visualize data. Besides, it will be possible to visualize and access data (for download) on the project website using the web application.

\section{CONCLUSION}

The research described in this paper was conveyed as a part of interregional project between Italy and Switzerland, called SIMILE. The project goal is the development of strategies for the conservation of three major lakes in Insubria region (Maggiore, Como and Lugano lakes) thanks to water quality monitoring with innovative solutions.

The initial step of the research was the analysis of past/ongoing projects, technological solutions that are dealing with water quality monitoring, implementing the concept of citizen science. More specifically, the focus was on smartphone applications that can be used to collect, process, publish and visualize water quality data. The final goal was to check the availability of a free and open source application for water quality monitoring.
Despite the fact that many applications for water quality monitoring are freely available, none of them is open source. Due to that, the design of a new application is presented in this paper. The application, which is at the designing stage, will be free and open source. Moreover, all the elements of the application (both client and server side) will be free and open source.

The application is being designed in such a way that needs and requirements of different stakeholders (scientists, decision makers and citizens) are met. Also, the design was driven by the idea of simplicity. Due to that, the data collection is split in four tasks, according to the level of difficulty. Users will have opportunity to accomplish one or more of them, depending on its expertise. The smartphone application will be complemented with a web application, allowing visualization and download of collected data. In the next stage, the mobile and web applications will be implemented and tested with a first group stakeholders.

\section{ACKNOWLEDGMENTS}

We would like to thank to the Interreg Europe, funder of SIMILE (ID523544) project, in the framework of which this research has been developed. The authors wish to thank also Michela Rogora (IRSA CNR) and Mariano Bresciani (IREA CNR) for the help in the definition of the specifications for the new application and for their contribution for the review of the existing applications.

\section{REFERENCE}

Bonnor, M. (2015). Nyt loppuu arvailu - kännykkäsovellus kertoo mökkijärvesi vedenlaadun. Retrieved 20 5, 2019, from https://yle.fi/uutiset/3-8083920

Boss, E., Taylor, L., Gilbert, S., Gundersen, K., Hawley, N., Janzen, C., . . al., e. (2009). Comparison of inherent optical properties as a surrogate for particulate matter concentration in coastal waters. Limnology and Oceanography(7), 803-810.

Brovelli, M., Wu, H., Minghini, M., Molinari, M., Kilsedar, C., Zheng, X., . . . Chen, J. (2018). OPEN SOURCE SOFTWARE AND OPEN EDUCATIONAL MATERIAL ON LAND. XLII-4, pp. 61-68. Delft, The Netherlands: Int. Arch. Photogramm. Remote Sens. Spatial Inf. Sci. doi:10.5194/isprs-archivesXLII-4-61-2018

Busch, J. A., Bardaji, R., Ceccaroni, L., Friedrichs, A., Jaume, P., Simon, C., .. . Zielinski, O. (2016). Citizen BioOptical Observations from Coast- and Ocean and Their Compatibility with Ocean Colour. Remote Sensing, 879-898. doi:10.3390/rs8110879

Citclops. (2014). Measuring water color. Retrieved May 2, 2019, from http://www.citclops.eu/watercolour/measuring-water-colour

Elsevier, B. (2019). Scopus. Retrieved 3 3, 2019, from https://www.scopus.com

Flagg, B. N. (2016). Contribution of Multimedia to Girls' Experience of Citizen Science. Citizen Science: Theory and Practice, 1(2), 1-13. doi:10.5334/cstp.51

Fritz, S., See, L., \& Brovelli, M. (2017). Motivating and Sustaining Participation in VGI. In G. Foody, L. See, S. Fritz, P. Mooney, A.-M. Olteanu-Raimond, C. C. Fonte, \& V. Antoniou (Eds.), Mapping and Citizen Sensor (pp. 93-117). London: Ubiquity Press. doi:10.5334/bbf.e. License: CC-BY 4.0 
Garbarino, J., \& Mason, C. E. (2016). The Power of Engaging Citizen Scientists for Scientific Progress. Journal of Microbiology \& Biology Education, 7-12. doi:10.1128/jmbe.v17i1.1052

Hijmans, R. (2019). DIVA-GIS. Retrieved 5 20, 2019, from https://www.diva-gis.org/Data

Kaukonen, L., \& Bruun, E. (2015). IQwtr-validation report. Finnish Environmental Institute.

Kullenberg, C., \& Kasperowski, D. (2016). What Is Citizen Science? - A Scientometric. PLoS ONE, 11(1). doi:10.1371/journal.pone.0147152

Lane, N. D., Miluzzo, E., Lu, H., Peebles, D., Choudhury, T., \& Campbell, A. T. (2010). A survey of mobile phone sensing. IEEE Communications Magazine, 48(9), 140-150. doi:10.1109/MCOM.2010.5560598

Leeuw, T., \& Boss, E. (2018). The HydroColor App: Above Water Measurements of Remote Sensing Reflectance and Turbidity Using a Smartphone Camera. Sensors, 18(1), 15. doi:10.3390/s 18010256

Liu, J., Yang, H., Gosling, S. N., Kummu, M., Flörke, M., Pfister, S., . . . Oki, T. (2017). Water scarcity assessments in the past, present, and future. Earth's Future, 5(6), 545-559.

Loiselle, S. A., Gasparini Fernandes, D. C., Shupe, S., Valiente, E., Rocha, L., Heasley, E., . . Baruch, A. (2016). Micro and Macroscale Drivers of Nutrient Concentrations in Urban Streams in South, Central and North America. PLos One, 11(9), 16. doi:10.1371/journal.pone.0162684

McGoff, E., Dunn, F., Cachazo, L. M., Williams, P., Biggs, J., Nicolet, P., \& C., E. N. (2017). Finding clean water habitats in urban landscapes: professional researcher vs citizen science approaches. Sience of the total environment, 581-285, 105-116. doi:10.1016/j.scitotenv.2016.11.215

Nielsen, J. (2006, October). The 90-9-1 Rule for Participation Inequality in Social Media and Online Communities. Retrieved June 5, 2019, from Nielsen Norman Group: https://www.nngroup.com/articles/participationinequality/

Novoa, S., Wernand, M., \& Van der Woerd, H. (2013). The forel-ule scale revisited sprectrally: Preparation protocol, transmission measurements and chromaticity. Journal of European Optical Society, 8. doi: 10.2971/jeos.2013.13057

Novoa, S., Wernand, M., \& Van der Woerd, H. (2015). A generic algorithm to derive the intrinsic color of natural waters from digital images. Limnology and Oceanography Methods(13), 697-711. doi:10.1002/lom3.10059

OED. (2019). OED, Oxford English Dictionary. Retrieved 5 24, 2019, from https://www.oed.com

Olteanu-Raimond, A.-M., Laakso, M., Antoniou, V., Fonte, C. C., Fonseca, A., Grus, M., . . Skopeliti, A. (2017). VGI in National Mapping Agencies: Experiences and Recommendations. In G. Foody, L. See, S. Fritz, P. Mooney, A.-M. Olteanu-Raimond, C. C. Fonte, \& V. Antoniou, Mapping and the Citizen Sensor (pp. 299326). London: Ubiquity Press.

Plymoth Marine Laboratory. (2019). MONOCLE. Retrieved 5 22, 2019, from http://monocle-h2020.eu/About

Seafarers, S., S, L., G, B., N, O., N, B., D, C., \& al., e. (2017). Seafarer citizen scientist ocean transparency data as a resource for phytoplankton and climate research. PLOS ONE, 12(12).
Solimini, A. G., Cardoso, A. C., \& Heiskanen, A.-S. (2006). Indicators and methods for the eological status assessment under the Water Framework Directive. Luxembpurg: Office for Official Publications of the European Communities.

Vincent, A., Drag, N., Lyandres, O., Neville, S., \& Hoellein, T. (2017). Citizen science datasets reveal drivers of spatial and temporal variation for anthropogenic litter on Great Lakes beaches. Science of the total environment, $\quad 577, \quad 105-112$. doi:10.1016/j.scitotenv.2016.10.113

Yuchao, Z., Ronghua, M., Minqi, H., Juhua, L., Jing, L., \& Qichun, L. (2017). Combining citizen science and land use data to identify drivers of eutrophication in the Huangpu River system. Science of total environment, 584-585, 651-664. doi:10.1016/j.scitotenv.2017.01.093 